\title{
An analysis on the Emotional Intelligence and Academic Achievement among the students in the District of Kottayam, Kerala
}

\author{
Elizabeth john, K. Manimekhalai
}

\begin{abstract}
Academic achievement considered as self-perception and self-evaluation of one's objective academic success. Academic achievement indicates the learning outcomes of pupil. Achievement of those learning outcomes requires a series of planned and organized experiences. There is equal gender participation in the study. Among the respondents 17 boys and 18 girls shown high level of Emotional Intelligence. Out of 50 respondents 16 boys and 17 girls shown high level of academic achievement. There is a strong positive correlation between emotional Intelligence and Academic Achievement.
\end{abstract}

Key Words: Emotional Intelligence, Academic achievement, Adolescents,

\section{INTRODUCTION}

This article will give essential information on what EQ is how it is different from personality, and how it has proven to impact the rural and urban students in their academic performance. Emotional Intelligence (EQ) is the emerging concept. There is a controversy among researchers that EI can be learned and taught and whether this EI will help the students' to succeed in school and in life. Emotional Intelligence is the concept which is very practical in nature and seems to be very essential for the development of the human life. The researchers still believe in the philosophy that intelligence and success are proportional to one another but now they are not viewed in the same way. The students are not because of the deviations from the basics. The present day focus the success of the student not only on their reasoning capacities as well on the self awareness, emotions, and interpersonal skills. The Emotional Intelligence theory by Bar-On in 1988, Mayer and Salovey in 1990, and Goleman in 1995. This theory of emotional intelligence gave a new aspect that the intelligence quotient (IQ) is not the only measure for success. Emotional intelligence is the tamper of projections with the view point of education which brings out the best in students not only just in academic achievement. It specifies that the EQ competencies are needed to enhance the personal skills leading to success in academics. The students who are excellent academically seem that the education system has not provided them the subjects to lead their life happily and to shape them productive citizens. According to this theory learning the skills which are necessary to function effectively in life are more important than achieving academically. The EQ idealists believe that the students who achieve academically have not yet developed their emotional

Revised Manuscript Received on July 08, 2019.

ELIZABETH JOHN, Research Scholar, Department of Social Work, Alagappa University, Karaikkudi, Tamil Nadu. Amst1920@gmail.com

Dr. K. MANIMEKHALAI Research Guide, Department of Social Work, Alagappa University, Karaikkudi, Tamil Nadu . intelligence and are not likely able to achieve their full capacity. The students do perform well unless and until they are engaged in developing their emotions, learning styles, personality and motivation.

Academic achievement is considered as a key criterion to judge one's total potentialities and capabilities. Therefore it is more pressing for the individuals/ students to have high academic achievement. The term achievement refers to the degree or the level of success attainted in some specific school tasks especially scholastic performance, in this sense academic achievement means the attained ability to perform school tasks, which can be general or specific to a given subject matter. Academic achievement could be defined as self-perception and self-evaluation of one's objective academic success. Academic achievement generally indicates the learning outcomes of pupil. Achievement of those learning outcomes requires a series of planned and organized experiences. Academic achievement as knowledge attitude or skill developed in the school subject usually designed by test scores or by marks assigned by teacher or by both. Consequently, academic achievement could be defined as self perception and self evaluation of one's objective success.

\section{DifFERENT Models of EMotional InTELLigence}

The Mixed Model and the Bar-On have given the following conceptual layouts: The Goleman model classifies EQ as a sequence with varied competencies that enhances managerial performance; defining it as "the abilities to recognize and regulate emotions in ourselves and in others. Bar-On (2006) $\mathrm{EQ}$ is measured through multi-rates assessment methods. The Bar-on model, defined as a model that describes "a cross section of interrelated emotional and social competencies, skills and facilitators that impact intelligent behaviour, measured by self-report within a potentially expandable multi-modal approach including interview and multi-ratter assessment".

The Ability Model The other definition of EQ which is supported by Salovey and Mayer is defined as "the ability to monitor ones and other's feelings and emotions, to discriminate among them and to use this information to guide one's thinking and action". This is the definition which is supported and accepted by most academicians, even Goleman and Bar-on, since it does not get in the way with their model.

\section{Review of Literature}

Mihaela, Stomff. (2014) The participants for this research were 70 adolescents: 35 
adolescents chosen from regular families and 35 teenagers who were raised in foster care institution. The results of the study showing the differences between the two categories that the adolescents raised in a normal family environment had higher marks at self-esteem, general and emotional evaluations.

Buško, Vesna., and Čikeš, Ana Babić. (2013) The paper presents a part of empirical validation procedures on emotional intelligence as operationalised by two different assessment methods but derived from the same ability-based conceptualization. The study was conducted on a sample of $180,7^{\text {th }}$ and $8^{\text {th }}$ grade school students. Peer-rated emotional regulation abilities showed considerable additive contribution to the criterion variance, whereas the role of Emotion management test within the predictor structure examined proved to be practically and statistically insignificant.

\section{Statement of the problem}

Academic achievement is an important factor in every student's life, especially in their high school and college years. But it is the age where they got distracted due to their peer group pressure, socialization, identity crisis etc:. The study is dealing study among the students living in the rural areas of Kottayam District, Kerala.

\section{Scope}

The study aimed to find out the relationship between emotional intelligence and academic achievement among adolescents, who are they need a correct strategy to cope up with distracting environments and need to attain academic achievement the better life for secured future. In this point the study of the emotional intelligence and academic achievements are important. The need of emotional Intelligence is a vital factor that enables the adolescents to attain their milestones

\section{Objectives}

i) To measure the level of Emotional Intelligence among the adolescent students

ii) To ascertain the level of academic achievement among the adolescent students

iii) To measure the relationship between Emotional Intelligence and academic achievement among the adolescent students

\section{RESEARCH METHODOLOGY}

A study among the students living in the rural areas of Kottayam District, Kerala. This section describes the study in a systematic and scientific way as follows:-

\section{Research Design}

The design study was made in accordance with the data collection and analysis. The study consisted of descriptive and exploratory analysis. The data was collected from both the primary and the secondary sources. The opinion of the respondents was collected through the questionnaire. Secondary data was gathered from various Publishing sources including Magazines, Journals, News Papers and Online resources. For the study survey sample size was taken, by choosing stratified random sampling method. The respondents were the students living in the rural areas of Kottayam District. The sample size consists of 50.

\section{DATA ANALYSIS \& INTERPRETATION}

Table No.1

\begin{tabular}{|l|l|l|}
\hline Gender & number & Per cent \\
\hline Boys & 25 & 50 \\
\hline Girls & 25 & 50 \\
\hline
\end{tabular}

Gender Distribution of the Respondents

*Source: Primary data

Table No.1 shows that there is equal gender participation (Boys 25 and Girls 25) in the number of respondents.

Table No. 2

Level of Emotional Intelligence among the Adolescents

Table No.3

\begin{tabular}{|l|l|l|l|}
\hline Gender & \multicolumn{3}{|l|}{ Level of Emotional Intelligence } \\
\cline { 2 - 4 } & Low & Medium & High \\
\hline Boys & 0 & 8 & 17 \\
\hline Girls & 0 & 7 & 18 \\
\hline
\end{tabular}

* Source: Primary data

Table No. 2 shows that there, out of out of 25 boys 17 respondents has high level of Emotional Intelligence, 8 has medium level of Emotional Intelligence and no one has low level of Emotional Intelligence. Out of out of 25 girls 18 respondents has high level of Emotional Intelligence, 7 has medium level of Emotional Intelligence and no one has low level of Emotional Intelligence .

Level of Academic Achievements among the Adolescents

\begin{tabular}{|c|c|c|c|}
\hline \multirow{2}{*}{ Gender } & \multicolumn{3}{|c|}{ Level of Academic Achievements } \\
\cline { 2 - 4 } & Low & Medium & High \\
\hline Boys & 3 & 6 & 16 \\
\hline Girls & 3 & 5 & 17 \\
\hline
\end{tabular}

*Source: Primary data

Table No. 3 shows that there, out of out of 25 boys 16 respondents has high level Academic Achievement, 6 has medium level of Academic Achievement and 3 has low level of Academic Achievement. Out of out of 25 girls 17 respondents has high level of Academic Achievement, 5 has medium level of Academic Achievement and 3 one has low level of Emotional Intelligence.

Table No.4 
Correlation between Emotional Intelligence and Academic Achievement among Adolescents

\begin{tabular}{|c|c|c|}
\hline Correlations & $\begin{array}{c}\text { Emotional } \\
\text { Intelligence }\end{array}$ & $\begin{array}{c}\text { Academic } \\
\text { Stress }\end{array}$ \\
\hline $\begin{array}{c}\text { Academic stress } \\
\text { Emotional } \\
\text { Intelligence } \\
\text { (Sign.2) } \\
\mathrm{N}\end{array}$ & 1 & .878 \\
\hline $\begin{array}{c}\text { Emotional } \\
\text { Intelligence } \\
\text { Academic stress } \\
\text { (Sign.2) } \\
\mathrm{N}\end{array}$ & 50 & \\
\hline
\end{tabular}

*Source: Primary data

Table No.4 shows that there is strong positive correlation between emotional Intelligence and Academic Achievement. Findings

There is equal gender participation (Boys 25 and Girls 25) in the study. Among the respondents 17 boys and 18 girls shown high level of Emotional Intelligence. Out of 50 respondents 16 boys and 17 girls shown high level of academic achievement. There is a strong positive correlation between emotional Intelligence and Academic Achievement.

\section{Conclusion}

The study shows that the boys and girls are equally emotionally intelligent and have same level of academic achievement. The study deals with the adolescents in the district of Kottayam, Kerala.

\section{REFERENCES}

1. Goleman, D. (1995) Emotional intelligence. London: Bloomsbury Publishing.

2. Goleman, D. (1995) Emotional Intelligence: Why it can matter more than IQ. . New York: Bantam.

3. Mayer, J. D., \& Salovey, P. (1997). What is emotional intelligence? New York: Basic Books.

4. Michael, A. (2005) Diagnosis in modern education. Damascus: Damascus University Press.

5. Buško1 ,Vesna., and Babić Čikeš, Ana.(2013) Emotional intelligence in early adolescence: Validation data based on peer ratings and an objective ability-based test. International Journal of Humanities and Social Science Invention.Vol.2 Issue .5, pp:54-62.

6. Balluerkaa, Nekane., Aritzetaa , Aitor., Gorostiagaa, Arantxa., Gartziab, Leire., and Soroaa, Goretti.(2013) Emotional intelligence and depressed mood in adolescence: A multilevel approach. International Journal of Clinical and Health Psychology.Vol. 13, pp:110-117.

7. www.danielgoleman.info

8. www.psychologytoday.com

9. www.positivepsychologyprogramme.com

10. www.inc.com

\section{AUTHORS PROFILE}

ELIZABETH JOHN , Research Scholar, Department of Social Work , Alagappa University, Karaikkudi, Tamil Nadu. Amst1920@gmail.com

Dr. K. MANIMEKHALAI Research Guide, Department of Social Work , Alagappa University, Karaikkudi, Tamil Nadu . 